\title{
DINÂMICA REGIONAL BRASILEIRA: UMA ANÁLISE COM BASE NOS DADOS DO PIB MUNICIPAL (2002-2015)
}

\author{
Fernando Cézar de Macedo ${ }^{1}$ \\ Leonardo Rodrigues Porto ${ }^{2}$
}

Resumo: O presente texto apresenta uma discussão metodológica e uma breve análise regional dos dados de Produto Interno Bruto dos Municípios - ano de referência 2010, divulgados pelo IBGE, para o período de 2002 a 2015. O objetivo é contribuir para maior entendimento da dinâmica regional no país no período considerado. Dentre as conclusões destacam-se: a) a histórica e persistente concentração espacial da riqueza; b) a continuidade do processo de desindustrialização, com perdas de participação da indústria de transformação nos municípios brasileiros; c) a dependência que ampla maioria dos municípios tem dos gastos do setor público; d) um lento, mas contínuo, processo de desconcentração econômica; e) falta de correlação entre elevados PIBs per capita municipais e bem-estar-social.

Palavras-chave: PIB municipal. Desenvolvimento regional. Desigualdade regional

\footnotetext{
${ }^{1}$ Professor do IE-Unicamp e pesquisador do Centro de Estudos do Desenvolvimento Econômico CEDE. Pesquisador Visitante do IPEA. E-mail: fernando.cezar.macedo@gmail.com.

${ }^{2}$ Doutorando em Desenvolvimento Econômico pelo IE-Unicamp e pesquisador do Centro de Estudos do Desenvolvimento Econômico - CEDE. Bolsista do CNPq e ex-bolsista do IPEA. E-mail:

Inrdporto@gmail.com
} 


\section{APRESENTAÇÃO}

Este trabalho visa contribuir para o entendimento da dinâmica regional brasileira, a partir das informações do Produto Interno Bruto (PIB) dos municípios, disponibilizadas pelo Instituto Brasileiro de Geografia e Estatística (IBGE). Toma-se por base a nova série, com ano de Referência 2010.

As informações levantadas do PIB municipal merecem especial atenção porque consistem na principal referência e mais importante base de dados a respeito das diferentes dinâmicas econômicas regionais, com disponibilidade anual, permitindo análises mais consistentes em diferentes níveis escalares, bem como comparações intertemporais vertical ou horizontalizadas. Deste modo, além da discussão metodológica, o presente texto lastreia-se, ainda, numa breve análise da evolução do PIB municipal no período recente (2002-2015), permitindo diagnosticar alguns aspectos da dinâmica regional brasileira, que ajudem a entender, a partir do âmbito municipal, a dinâmica regional e urbana brasileira. Para reforçar sua importância, basta mencionar que a Política Nacional de Desenvolvimento Regional (PNDR) se baseia nesta informação para classificar as Microrregiões brasileiras para fins de ação.

\section{VANTAGENS E LIMITES DA NOVA SÉRIE DO PIB DOS MUNICÍPIOS - REFERÊNCIA 2010: ASPECTOS METODOLÓGICOS}

O IBGE adotou a partir da publicação de 2016 (referente às informações de 2014) uma atualização metodológica do cálculo do PIB municipal. O primeiro aspecto relacionado à nova metodologia do PIB dos Municípios - Ano de Referência 2010, é que o cálculo "obedece a uma Metodologia uniforme para todas as Unidades da Federação e é integrado, conceitualmente, aos procedimentos adotados nos Sistemas de Contas Nacionais e Regionais do Brasil". Deste ponto de vista, a série difere bastante das anteriormente utilizadas para o período pré-1999, pois permite uma maior coerência e a comparação entre si e com os resultados nacional e regionais ${ }^{3}$.

Estes novos procedimentos adotados pelas Contas Nacionais e Contas Regionais seguem as regras internacionais divulgadas pelo System National Accounts

3 Para uma visão detalhada das mudanças metodológicas da nova série do PIB, ver a Nota metodológica da série do PIB dos Municípios - Referência 2010 (IBGE, 2015). 
(SNA-2008), pela Organização das Nações Unidas (ONU) e as modificações têm impactos no peso relativo das atividades econômicas na geração do valor adicionado bruto. Com isto, "o novo vetor de peso das atividades econômicas refletiu, diretamente, na composição do PIB dos municípios"4. O fato é que o PIB municipal é calculado com base na "distribuição, entre os municípios, do valor adicionado bruto - a preços básicos -, em valores correntes das atividades econômicas, obtido pelas Contas Regionais do Brasil” ${ }^{5}$. É neste sentido que a nova metodologia implica, necessariamente, na revisão dos indicadores utilizados na distribuição de tais variáveis entre os municípios ${ }^{6}$ e, portanto, torna mais importante uma reclassificação para fins de políticas territoriais.

Dentre as principais mudanças apontadas pelo IBGE que a nova metodologia do PIB desenvolve, em relação à anterior (ano de referência 2002), para distribuição do valor adicionado entre os municípios estão: a) maior relevância da produção secundária para a distribuição do VAB agropecuário; b) o VAB das indústrias que são mais concentradas nas UFs passa a ser alocado nos municípios com a presença da referida atividade industrial (ex.: indústria de refino e celulose); e c) a distribuição do VAB das atividades de comércio atacadista somente entre os municípios com presença destas atividades (ex.: o comércio atacadista de combustíveis, que é concentrado). Todas estas são mudanças que afetam significativamente a distribuição do Valor Adicionado entre os municípios e, portanto, alteram uma das principais variáveis utilizadas para construção da Tipologia Sub-regional da PNDR, que é o PIB per capita.

Por fim, mas de grande importância, a metodologia atual do PIB municipal apresenta os VABs Total, da Agropecuária, da Indústria e dos Serviços. Porém, destaca-se pela abertura do VAB corrente da Administração, saúde e educação públicas e seguridade social, devido a sua importância no peso das economias municipais e fundamental para entender a heterogeneidade da dinâmica regional brasileira. Outra inovação setorial da série é a apresentação das três atividades econômicas de maior relevância em cada município. Embora, não seja uma informação

\footnotetext{
${ }^{4}$ Idem.

${ }^{5}$ IBGE (2015).

${ }^{6}$ Para conhecimento dos indicadores utilizados pelo IBGE para distribuição do valor adicionado entre os municípios, ver Série Relatórios Metodológicos, v. 29: Produto Interno Bruto dos Municípios, 2ª ed., que apresenta os indicadores de cada atividade.
} 
quantitativa, permite analisar qualitativamente o PIB dos municípios, enriquecendo bastante a análise.

Devemos ressaltar, contudo, algumas limitações da série. Conforme exposto anteriormente, a série utilizada vai do ano de 2002 a 2015. Porém, entre 2002 e 2009 ela é retropolada; e a partir de 2010 os dados são estimados para cada município ${ }^{7}$. De acordo com o IBGE, a série 2002-2009 baseia-se na retropolação de 15 atividades econômicas fornecidas pelas Contas Regionais (CRs) ${ }^{8}$. Os resultados de 2010 foram utilizados para produzir uma chave de repartição. Contudo, para alguns segmentos, a estimação requereu a utilização da variação da série anterior. Noutras atividades, foi necessário estimar o valor por um método indireto, baseado no cálculo da diferença entre as estruturas da série anterior (referência 2002) e da atual. Além disso, a série também lida com mudanças da CNAE 1.0 para a $2.0^{9}$.

Deve-se considerar que a retropolação, apesar das limitações, permitiu uma análise intertemporal mais consistente, ao colocar os valores numa mesma base de referência. Da mesma forma, possibilitou uma atualização dos parâmetros do PNDR, conforme destacado na última seção deste artigo.

\section{ANÁLISE DO PIB MUNICIPAL: OBSERVAÇÕES GERAIS SOBRE A DINÂMICA REGIONAL BRASILEIRA}

O movimento geral da economia brasileira ocorre sobre uma rede de cidades bastante distinta regionalmente e com diferentes tempos históricos, padrões culturais, estruturas produtivas, sociais, ambientais e, em especial, com diversas e variadas interações espaciais em múltiplas escalas. Esta rede estrutura-se a partir de uma

\footnotetext{
${ }^{7}$ O IBGE também divulgou uma Nota Metodológica para explicação da série retropolada (2002-2009). Ver Nota metodológica da série retropolada (2002-2009) PIB dos Municípios - Referência 2010 (IBGE, 2015). A leitura dessa Nota pode nos apresentar algumas limitações à construção do indicador para a PNDR.

8 As atividades econômicas cujos valores adicionados foram retropolados foram: 1-Agropecuária; 2Indústria extrativa mineral; 3- Indústria de transformação; 4- Produção e distribuição de eletricidade, gás, água, esgoto e limpeza urbana; 5- Construção civil; 6- Comércio, manutenção e reparação de veículos automotores e motocicletas; 7- Serviços de alojamento e alimentação; 8- Transportes, armazenagem e correio; 9- Serviços de informação; 10- Intermediação financeira, seguros e previdência complementar; 11- Atividades imobiliárias; 12- Atividades profissionais, científicas e técnicas, administrativas e serviços complementares; 13- Administração, educação e saúde públicas, defesa e seguridade social; 14Educação mercantil e Saúde mercantil e 15- Artes cultura, esporte e recreação e outras atividades de serviços e serviços domésticos.

${ }^{9}$ Ver Notas Metodológicas.
} 
miríade de 5.570 municípios muito desiguais em tamanho populacional, capacidade arrecadatória e, sobretudo, no perfil socioeconômico. Estes formam um mosaico variado de possibilidades (ou impossibilidades) para cada um deles se articular aos circuitos econômicos, sejam esses ligados aos mercados regionais, nacional ou internacional. Tais diferenças também definem a capacidade de oferta de serviços públicos que elevam a qualidade de vida em cada um deles.

A despeito da ainda forte e histórica concentração da produção e da renda nas regiões Sul e Sudeste, que apresentam redes de cidades mais estruturadas e articuladas, e do comando exercido pela metrópole paulistana sobre a organização socioeconômica do território brasileiro, observa-se um lento (muito lento), porém contínuo, processo de interiorização das atividades produtivas. Os gráficos 1 e 2 indicam o crescimento na participação dos municípios fora das regiões metropolitana no PIB total do país, ainda que este ganho, entre 2002 e 2015, tenha sido pequeno. Esta interiorização decorre, dentre outros fatores ${ }^{10}$, do padrão de reprodução do capital ${ }^{11}$ na economia do país que prevalece desde os anos 1980, mas que ganhou significativa força na primeira década do século XXI.

GRÁFICO 1 - BRASIL: Participação das 9 Regiões Metropolitanas criadas por lei federal e dos demais municípios no PIB brasileiro - Ano: 2002-2015 (em\%)

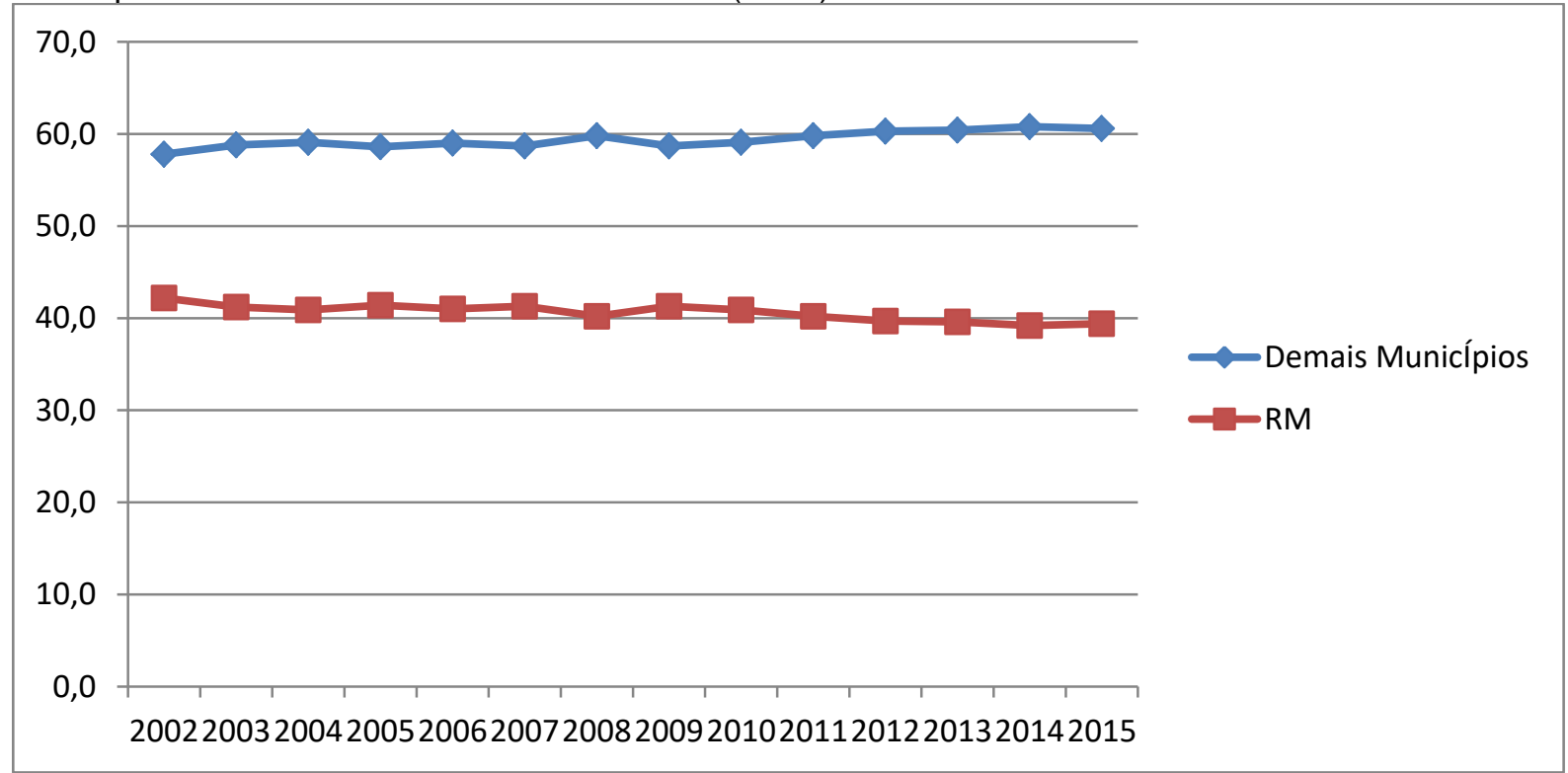

Fonte: IBGE/PIB Municipal. Elaboração dos autores

${ }_{11}^{10}$ Sobre o processo de desconcentração regional da produção no Brasil, ver especialmente Cano (2008).

${ }^{11}$ Sobre o conceito de padrão de reprodução do capital, ver Osório (2012a e 2012b). 
Dentre as principais características deste padrão, destacam-se duas em particular: 1) a desindustrialização que afeta diretamente os maiores centros urbanos do Brasil, especialmente no estado de São Paulo; 2) a especialização produtiva em atividades agropecuárias e minerais para a exportação, com as primeiras, mais interiorizadas, impulsionando a economia na região de fronteira agrícola, sobretudo no estado do Mato Grosso e nos cerrados nordestinos e, mais recentemente, na região do MATOPIBA $^{12}$. Já as atividades minerais são relativamente mais espraiadas pelo litoral, como no caso da extração de petróleo, mas ainda concentradas nos estados de Minas Gerais e do sudeste do Pará, no caso da extração de minerais metálicos. Contudo, há novas áreas de expansão como o Piauí ou áreas antigas, interiorizadas e espalhadas dispersamente pelo território. Da combinação destes dois fatores, observa-se maior dinamismo naquelas regiões e sub-regiões que produzem commodities para o mercado externo, conforme se discutirá adiante.

GRÁFICO 2 - BRASIL: Participação das Regiões Metropolitanas, Aglomerações Urbanas, RIDEs e dos demais municípios no PIB brasileiro - Ano: 2002-2015 (em\%)

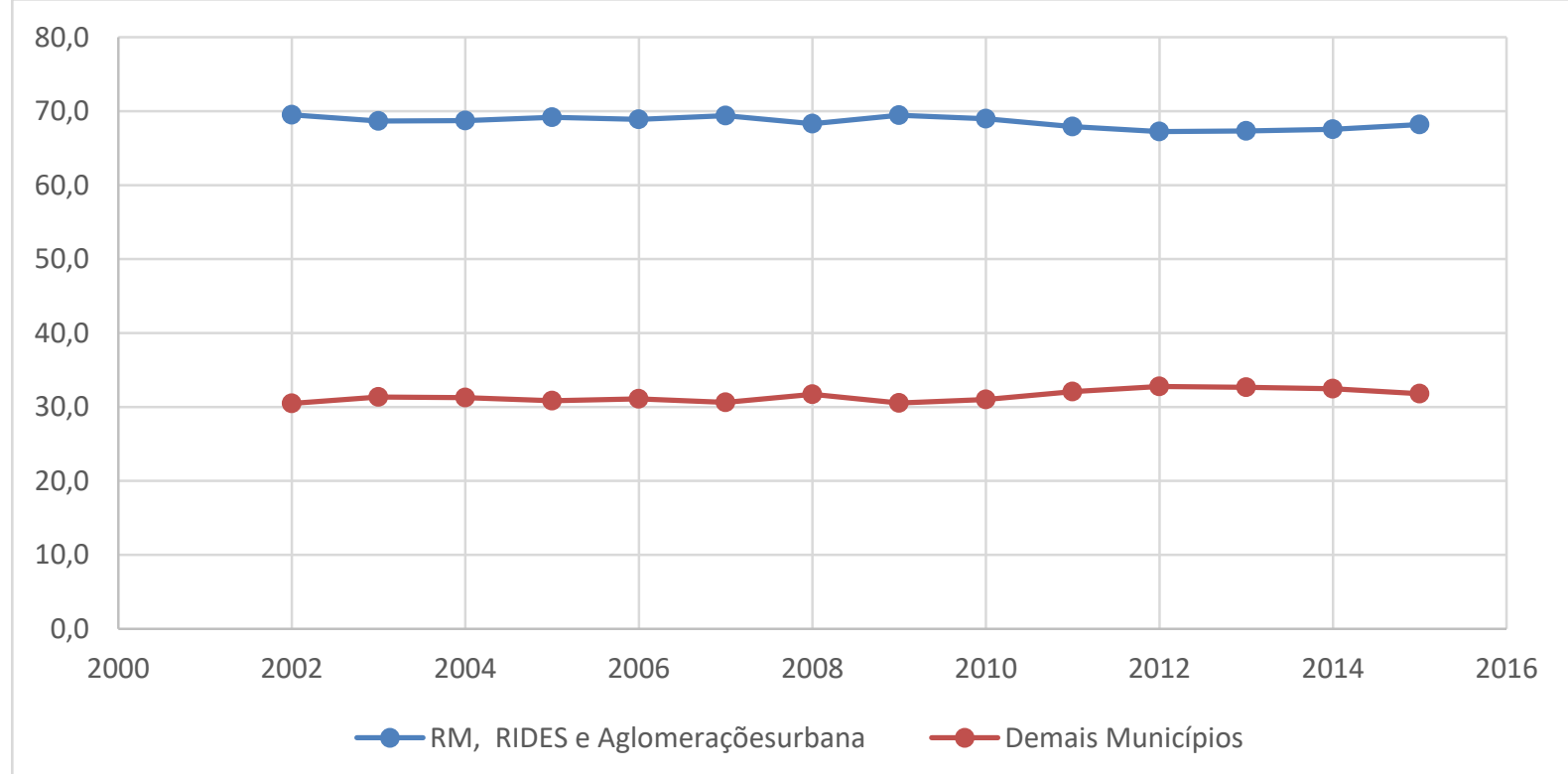

Fonte: IBGE/PIB Municipal. Elaboração dos autores.

\footnotetext{
${ }^{12}$ Nova região de desenvolvimento econômica criada, através do Decreto № 8.447, de 6 de maio de 2015, que dispõe sobre o Plano de Desenvolvimento Agropecuário do MATOPIBA e a criação de seu Comitê Gestor. A sigla representa as extensas áreas territoriais dos cerrados brasileiros existentes nos estados do Maranhão (MA), de Tocantins (TO), do Piauí (PI) e da Bahia (BA).
} 
Não obstante, a crise econômica a partir de 2014, afetou-lhes mais, pois o conjunto dos Demais Municípios, vis à vis as RM, RIDES e Aglomerações Urbanas (gráfico 2), perdeu 0,7 p.p. na participação total do PIB Municipal entre 2014 e 2015. Ou seja, a crise parece frear a pequena desconcentração econômica que se observa no país, especialmente pela queda nos preços internacionais das commodities.

Evidências da heterogeneidade do conjunto de cidades brasileira podem ser aferidas através da análise do documento Produto Interno Bruto dos Municípios, produzido pelo IBGE. Nele, observam-se uma gama de situações diferenciadas de municípios. Porém, ainda que a sua agregação em tipologias definidoras de grupos comuns seja muito difícil utilizando exclusivamente estas informações ${ }^{13}$, algumas características da evolução dos seus produtos podem ser elencadas, refletindo diretamente o movimento geral da economia brasileira em sua dimensão territorial. Dentre essas características, que são fundamentais para o entendimento da dinâmica regional e urbana recente no país, cabe destacar:

1) Forte concentração da riqueza. Em 2015, oito municípios concentravam mais de $26,0 \%$ do PIB embora representassem apenas $14,7 \%$ da população residente no país. Em contrapartida, 5.5244 respondiam por praticamente a mesma proporção $(26,1 \%)$ do PIB municipal, mas por $45,0 \%$ da população total. A Tabela 1 sintetiza esses dados. Há de se destacar, também, o caráter espacialmente concentrado do PIB nas capitais estaduais. Em quase todas as unidades federativas, a capital representa $\mathrm{O}$ município que detém a maior parcela do PIB. Exceção é Santa Catarina que tem uma rede de cidades mais desconcentrada, com vários municípios exercendo papel de polo regional, razão pela qual Florianópolis aparece como o segundo PIB catarinense.

\footnotetext{
${ }^{13}$ Esforço neste sentido, porém com um número muito grande de variáveis, são as pesquisas de Região de Influenciada Cidades realizadas pelo IBGE que classificam as cidades brasileiras em diferentes níveis hierárquico, de acordo com suas centralidades e interações espaciais.
} 
TABELA 1 - BRASIL: Produto Interno Bruto e População: distribuição segundo número selecionado de municípios - Ano $=2015$

\begin{tabular}{lcc}
\hline Municípios brasileiros & $\begin{array}{c}\text { \% do PIB que } \\
\text { concentravam }\end{array}$ & \% da população que concentravam \\
\hline 8 maiores & 26,0 & 14,7 \\
25 maiores & 37,7 & 23,5 \\
100 maiores & 56,4 & 38,1 \\
200 maiores & 67,0 & 48,0 \\
1.000 menores & 0,6 & 2,1 \\
5.244 menores & 26,1 & 45,0 \\
\hline
\end{tabular}

Fonte: IBGE/PIB Municipal e estimativa populacional/IBGE. Elaboração dos autores.

Ou seja, além de uma dimensão macrorregional da concentração do PIB com o Sudeste respondendo por $54,0 \%$ do seu total, há uma outra (capital $x$ interior) que reflete importante aspecto que não pode ser negligenciado na política regional brasileira: a concentração intraestadual da riqueza ${ }^{14}$. Se fizéssemos um exercício similar da tabela 1 para as unidades federativas, verificaríamos que os cinco maiores municípios em cada uma delas concentravam parcela expressiva da riqueza, conforme consta nos documentos do IBGE (2016 e 2017). Isso significa que o esforço para diminuir os "desequilíbrios regionais" do país deve estar articulado às políticas estaduais de desenvolvimento e interiorização, buscando adensar as redes urbanas sub-regionais e elevar a oferta pública de serviços e infraestrutura de forma a melhorar as condições de vida do interior e aumentar as possibilidades de geração de emprego e renda nele.

2) Queda na participação da indústria de transformação que passou de 15,0\% do total do PIB municipal em 2010 para 12,2\% em 2015. Esse desempenho reflete a crise na economia brasileira mas também decorre do processo estrutural de desindustrialização, conforme discutido por diversos autores ${ }^{15}$. Do ponto de vista regional e urbano, este fenômeno significa que a indústria de transformação responde cada vez menos pela organização socioespacial do país conforme ocorrera no período de 1930 a 1980, marcado pelo padrão urbano-industrial de reprodução do capital. Não

\footnotetext{
${ }^{14}$ Da mesma forma, o problema da concentração intrarregional que não é levada, mormente, em conta quando da formulação das políticas que, geralmente, tratam as regiões-alvo agregadamente, sem considerar suas múltiplas diferenças internas. Diversos trabalhos demonstram isso para o caso da aplicação dos recursos dos fundos constitucionais como Macedo, Sampaio e Pires (2017), Macedo e Matos (2008) e Macedo e Coelho (2016).

${ }^{15}$ Uma síntese do processo de desindustrialização brasileira, especialmente em sua dimensão regional, encontra-se em Sampaio (2015).
} 
obstante, ela continua estratégica para uma política de adensamento das cadeias produtivas e diversificação da base econômica, contribuindo para reduzir a vulnerabilidade externa brasileira e sua dependência de commodities exportáveis de baixo valor agregado. Deve-se registrar, no entanto, que em relação à 2014 a indústria de transformação ganhou 0,2 p. p. no total do PIB municipal.

\section{3) Forte dependência do setor público na formação do PIB municipal.}

Em 2015, 2.806 municípios brasileiros, ou 50,4\% do total deles, tinham como principal atividade na formação de seus PIBs o segmento Administração, saúde e educação públicas e seguridade social. Esta dependência variava de 82,0\% em Uiramutã (RR) a $1,7 \%$ em Presidente Kennedy (ES), município com estrutura produtiva fortemente especializada, atrelada à extração de petróleo, e que apresentava o maior PIB per capita do país. Do total de 5.570 municípios brasileiros, 2.550 , ou $45,8 \%$ deles, a administração pública representava um terço ou mais do PIB em 2015. Assim como outros indicadores, este também tem um claro corte regional com os municípios das regiões Norte e Nordeste apresentando maior dependência do setor público, conforme se observa na Figura 1, que traz a agregação por microrregião do IBGE.

Esta dependência torna-se ainda maior na medida em que se localizam naquelas regiões as cidades mais beneficiadas pelas políticas públicas de transferência de renda. Ou seja, são áreas que, com a crise na economia brasileira e o processo de ajuste fiscal neoliberal a partir de 2015, tendem a sofrer com maior intensidade os efeitos dos cortes no gasto público. Ademais, o maior peso do setor púbico no PIB se dá naqueles municípios de menor porte populacional (tabela 2), e que apresentam menor capacidade arrecadatória, portanto, dependentes dos repasses de fundos públicos. Por meio da referida tabela, observamos que esse peso decresce à medida que o tamanho do município se amplia.

Deve-se notar, porém, que mesmo nos municípios de maior porte, situados em áreas de menor adensamento econômico e com redes urbanas menos equilibradas, esta dependência faz-se sentir quando a observamos na escala da rede urbana, ou da área de influência em que eles atuam. O caso foi demonstrado por Porto (2016), particularmente para as cidades das regiões semiáridas do Nordeste em que, apesar do relativo dinamismo dos serviços no âmbito de seus municípios, o fato de atuarem sobre 
um conjunto regional cuja principal fonte de renda advém do gasto público e das políticas federais de transferência de renda, as coloca sob evidente fragilidade.

FIGURA 1 - BRASIL: Índice de participação da Administração, saúde e educação públicas e seguridade social no PIB, por município - Ano $=2015$

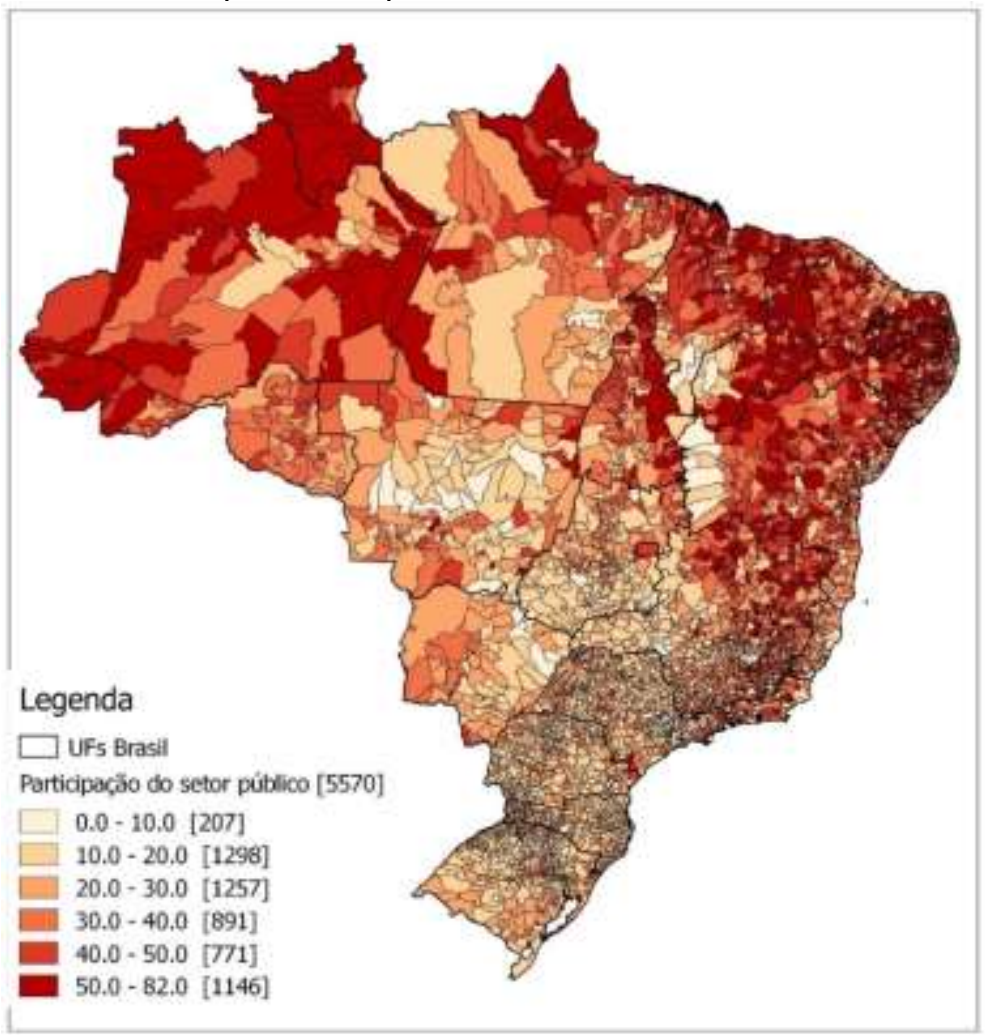

Fonte: IBGE/PIB Municipal. Elaboração dos autores.

TABELA 2 - BRASIL: Distribuição das atividades com maior VAB em relação ao PIB, segundo classe de tamanho populacional do município (em \%) - Ano= 2015

\begin{tabular}{|c|c|c|c|c|c|c|c|c|c|c|c|}
\hline Tamanho Populacional & $\begin{array}{l}\frac{\pi}{3} \\
\frac{T}{5} \\
\frac{0}{5} \\
\frac{0}{4}\end{array}$ & 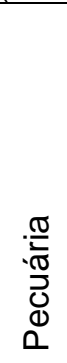 & 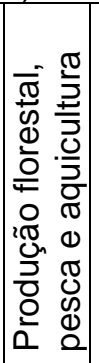 & 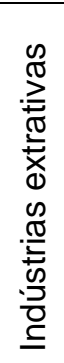 & 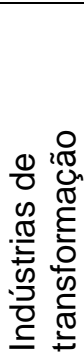 & 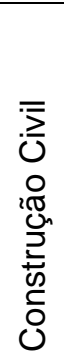 & 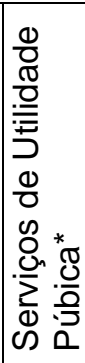 & 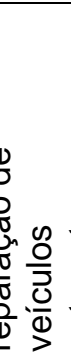 & 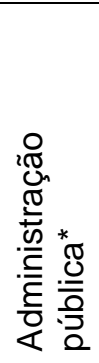 & 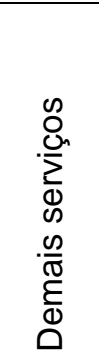 & $\begin{array}{l}\bar{\pi} \\
\text { त्र }\end{array}$ \\
\hline Até 5 mil & 19,3 & 7,5 & 0,7 & 0,4 & 3,9 & 0,2 & 1,5 & 1,1 & 57,7 & 7,6 & 100,0 \\
\hline$>5$ mil e $<20$ mil & 10,1 & 2,1 & 0.5 & 1,3 & 5,1 & 0,3 & 1,7 & 0,7 & 56.6 & 21,6 & 100.0 \\
\hline$>20 \mathrm{mil} \mathrm{e}<50 \mathrm{mil}$ & 5,1 & 0,5 & 0,5 & 1,6 & 5,6 & 0,3 & 1,7 & 0,9 & 46,2 & 37,4 & 100,0 \\
\hline$>50 \mathrm{mil} \mathrm{e}<100 \mathrm{mil}$ & 2,6 & 0,6 & 0,0 & 2,0 & 8,8 & 0,0 & 0,0 & 2,3 & 26,5 & 57,3 & 100,0 \\
\hline$>100$ mil e $<250$ mil & 0,0 & 0,5 & 0,0 & 3,1 & 5,2 & 0,5 & 1,5 & 1,0 & 12,4 & 75,8 & 100,0 \\
\hline$>250 \mathrm{mil} \mathrm{e}<500 \mathrm{mil}$ & 0,0 & 0,0 & 0,0 & 1,4 & 7,2 & 0,0 & 1,4 & 0,0 & 5,8 & 84,1 & 100,0 \\
\hline$>500$ mil e $<1$ milhão & 0,0 & 0,0 & 0,0 & 0,0 & 0,0 & 0,0 & 0,0 & 0,0 & 0,0 & 100,0 & 100,0 \\
\hline acima de 1 milhão & 0,0 & 0,0 & 0,0 & 0,0 & 5,9 & 0,0 & 0,0 & 0,0 & 11,8 & 82,4 & 100,0 \\
\hline
\end{tabular}

Fonte: IBGE/PIB Municipal. Elaboração dos autores.

*Inclui: Eletricidade e gás, água, esgoto, atividades de gestão de resíduos e descontaminação

**Inclui: Administração, saúde e educação públicas e seguridade social. 
Uma diferenciação, porém, é que os municípios de menor porte costumam carecer de atividades que thes dinamizem a economia local, seja voltada para o mercado interno (regional ou nacional) ou para o mercado externo. Trata-se de municipalidades com base produtiva pouco diversificada, na qual o comércio e os serviços, e mesmo a pequena indústria, giram em torno das atividades rurais e da renda advindas do setor público e das transferências governamentais. São, em geral, classificados como centros locais dentro da hierarquia urbana da REGIC/IBGE, ou seja, "cidades cuja centralidade e atuação não extrapolam os limites do seu município, servindo apenas aos seus habitantes" (IBGE, 2008, p. 13). Por essa razão, a administração pública - direta ou indiretamente - surge como principal vetor de circulação monetária e da demanda efetiva para um número considerável de municípios.

Já os municípios de médio e grande porte apresentam densidade suficiente para atraírem investimentos e ofertarem serviços um pouco mais sofisticados que dependem de economias de aglomeração e de urbanização. Por estas razões, as cidades de porte médio (entre 100 mil e 500 mil habitantes) e as grandes (acima de 500 mil habitantes) ${ }^{16}$ apresentam maior participação do setor terciário (comércio e serviços), além de serem as áreas prioritárias da localização da indústria no país. Portanto, possuem base econômica mais diversificada a Ihes tornarem mais atrativas aos investimentos privados.

Em outras palavras, onde o investimento privado não chega por não ser rentável - caso dos municípios de pequeno porte -, sobra o gasto público como elemento decisivo para a geração de emprego e renda locais. A presença do Estado constituiIhes o principal fermento econômico sem o qual não poderiam subsistir e/ou elevar a demanda efetiva. Por não serem atrativos ao capital, cuja única métrica é o lucro, estes municípios menores dependem do dispêndio público para movimentarem suas economias.

\footnotetext{
${ }^{16}$ Reconhece-se, aqui, que esta classificação dos municípios pelo tamanho populacional proposto é bastante precária e não reflete a diversidade regional e as especificidades que os mesmos apresentam, tornando-os bastante diferenciados de acordo com sua localização na rede urbana e nas regiões brasileiras. Trata-se de uma simplificação que ajuda, não obstante, a colocar - preliminarmente questões gerais que são importantes para o entendimento da dinâmica urbano-regional brasileira.
} 
Tais localidades se beneficiaram mais que a média nacional das políticas públicas praticadas na primeira década deste século. Políticas que ajudaram na continuidade da pequena desconcentração do PIB ocorrida durante o período no país. Dentre estas políticas, cabe destacar as de transferência de renda, a de valorização do salário mínimo, a de formalização do emprego e a do crescimento - ainda que tímido dos investimentos públicos, especialmente os federais. É por esta razão que a crise econômica, a queda na arrecadação e o ajuste restritivo praticado desde 2015 parecem ter-Ihes afetado com mais intensidade.

4) Lento processo de interiorização e de desconcentração da produção. O desempenho da economia brasileira tem sido bastante sofrível desde as duas últimas décadas do século passado quando seu PIB cresceu a taxas médias anuais de 1,6\% (década de 1980) e 2,5\% (década de 1990). No entanto, a partir de 2004 observa-se ritmo maior de crescimento em decorrência da expansão da demanda internacional de commodities, embora esta tenha se desacelerado a partir de $2013^{17}$.

$\mathrm{Na}$ primeira década do século XXI, o crescimento da economia chinesa, impulsionado pela rápida industrialização e sua correlata urbanização, pressionou para cima os preços das commodities, favorecendo os termos de trocas das economias cujas bases de exportação no padrão de reprodução do capital exportador de especialização produtiva se assentam em produtos intensivos em recursos naturais, como os países da América Latina e África. Se este período de dez anos, a partir de 2003, representou alguma melhora nos indicadores macroeconômicos do Brasil, ele também se mostrou contraditório, especialmente pela déblâce da indústria de transformação, conforme destacado. No entanto, regionalmente, a dependência das commodities beneficiaria áreas com disponibilidade de terras e recursos naturais, mormente localizadas no interior do Brasil, contribuindo para o processo - ainda lento e tímido - de desconcentração produtiva regional conforme se observa na Tabela 3. Percebe-se que a desconcentração econômica foi pequena; praticamente houve uma

17 Conforme destacaram Macedo, Sampaio e Pires (2015, p. 27), "entre 2003 e 2012, quando determinantes da política interna e o ritmo das exportações de commodities geraram efeitos dinâmicos sobre as economias regionais, especialmente Nordeste, Centro-Oeste e Norte do país, o PIB brasileiro cresceu em média 3,9\% a.a.". Em 2013, 2014 e 2015, a taxa de variação do PIB brasileiro foi de, respectivamente, $3,0 \% ; 0,5 \%$ e $-3,8 \%$. 
redistribuição da perda de participação do Sudeste em geral (-3,4 p. p.) e de São Paulo em particular (-2,5 p. p.) entre 2002 e 2015 para as demais regiões que, conjuntamente, ampliaram suas participações: Norte, +0,7 p. p.; Nordeste, $+1,1$ p. p.; Sul, +0,6 p. p.; Centro-Oeste, $+1,1$ p. p.).

TABELA 3 - BRASIL: Participação das Macrorregiões e do estado de São Paulo no PIB brasileiro - Ano: 2002-2015 (em\%)

\begin{tabular}{l|c|c|c|c|c|c|c|c|c|c|c|c|c|c}
\hline $\begin{array}{l}\text { Macrorregião } \\
\text { e UF } \\
\text { selecionada }\end{array}$ & $\mathbf{2 0 0 2}$ & $\mathbf{2 0 0 3}$ & $\mathbf{2 0 0 4}$ & $\mathbf{2 0 0 5}$ & $\mathbf{2 0 0 6}$ & $\mathbf{2 0 0 7}$ & $\mathbf{2 0 0 8}$ & $\mathbf{2 0 0 9}$ & $\mathbf{2 0 1 0}$ & $\mathbf{2 0 1 1}$ & $\mathbf{2 0 1 2}$ & $\mathbf{2 0 1 3}$ & $\mathbf{2 0 1 4}$ & $\mathbf{2 0 1 5}$ \\
\hline Norte & 4,7 & 4,7 & 5,0 & 4,9 & 5,0 & 5,0 & 5,0 & 5,0 & 5,3 & 5,5 & 5,4 & 5,5 & 5,3 & 5,4 \\
Nordeste & 13,1 & 12,8 & 12,9 & 13,0 & 13,2 & 13,0 & 13,1 & 13,6 & 13,5 & 13,3 & 13,6 & 13,6 & 13,9 & 14,2 \\
Sudeste & 57,4 & 56,5 & 56,5 & 57,5 & 57,7 & 57,4 & 57,0 & 56,3 & 56,1 & 56,1 & 55,9 & 55,3 & 54,9 & 54,0 \\
São Paulo & 34,9 & 34,4 & 33,4 & 34,2 & 34,2 & 34,4 & 33,5 & 33,8 & 33,3 & 32,8 & 32,4 & 32,2 & 32,2 & 32,4 \\
Sul & 16,2 & 17,1 & 16,8 & 15,9 & 15,6 & 16,1 & 16,0 & 15,9 & 16,0 & 15,9 & 15,9 & 16,5 & 16,4 & 16,8 \\
Centro-Oeste & 8,6 & 8,9 & 8,9 & 8,6 & 8,4 & 8,6 & 8,9 & 9,3 & 9,1 & 9,1 & 9,2 & 9,1 & 9,4 & 9,7 \\
\hline
\end{tabular}

Fonte: IBGE/PIB Municipal. Elaboração dos autores.

O crescimento da economia brasileira pós-2004 ocorreu em grande medida puxado por atividades localizadas no interior do país, especialmente nas regiões Norte, Nordeste e Centro-Oeste ${ }^{18}$. Isso foi importante porque contribuiu para amenizar os desequilíbrios espaciais. Porém, a reduzida desconcentração decorreu muito mais do movimento da economia mundial e do papel de produtor especializado do Brasil na divisão internacional do trabalho. Não é o resultado direto de políticas de desenvolvimento regional explícitas, como a PNDR, por exemplo. A Figura 2 apresenta as taxas de crescimento do PIB municipal agregado por microrregiões. Nela observa-se mosaico diferenciado de desempenho econômico, mas fica evidente o crescimento das microrregiões mais interiorizadas acima das médias das regiões Sudeste e Sul.

\footnotetext{
${ }^{18}$ Reconhece-se que diversos fatores contribuíram para o crescimento da economia brasileira pós-2003 e não apenas a expansão das commodities no mercado internacional. No entanto, considera-se que essa foi mais importante por possibilitar as condições favoráveis para o financiamento de muitas das políticas realizadas. Entre os vetores que tiveram importância para o crescimento da economia brasileira no período, muitas, inclusive, com forte impacto regional, cabe destacar: expansão do crédito doméstico, especialmente a partir da elevação do gasto público e dos investimentos em obras de infraestrutura, as políticas sociais e a expansão do consumo das famílias.
} 
FIGURA 2 - BRASIL: Taxa de variação do PIB municipal - Anos 2002 e 2015 (em \%) ${ }^{19}$

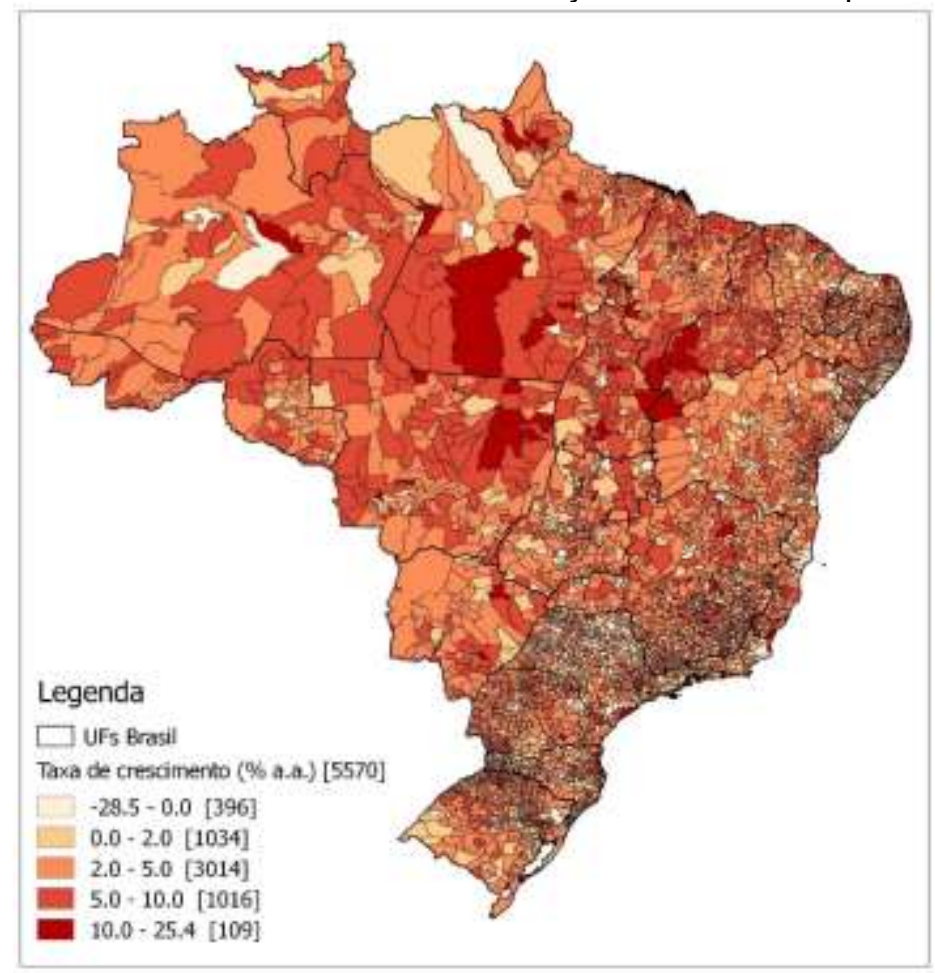

Fonte: IBGE/PIB Municipal. Elaboração dos autores.

5) A falsa ilusão do crescimento do PIB municipal. Aspecto a se destacar, decorrente do que foi exposto até agora, é a contribuição de trabalhos que apontam, por meio de indicadores diversos, a melhoria das condições de vida no interior que apresentaria um conjunto de cidades cujo crescimento recente as colocariam como locais em condições mais favoráveis para se morar. Ainda que exemplos não faltem para confirmar isso, deve-se registrar que em muitos destes municípios interiorizados e com maior crescimento econômico ocorrem os velhos problemas urbanos que são comuns e mais conhecidos nas regiões metropolitanas do Brasil, razão pela qual aquela constatação - apresentada a partir dos referidos indicadores, dentre os quais o de crescimento do PIB - deve ser relativizada. Isto porque, mesmo nestas áreas com maior dinamismo puxados pela expansão das commodities agrícolas e minerais, as velhas mazelas do subdesenvolvimento brasileiro se fazem presentes e exigem

\footnotetext{
${ }^{19}$ Para os municípios de Aroeiras do Itaim(PI), Figueirão (MS), Ipiranga do Norte (MT) e Itanhangá (MT), as taxas foram calculadas para o período 2005 e 2015. Para Nazária (PI), o período foi 2009-2015. Mojuí dos Campos (PA), Pescaria Brava (SC), Balneário Rincão (SC), Pinto Bandeira (RS) e Paraíso das Águas (MS), 2013-2015.
} 
políticas específicas para combinar dinamismo econômico, desconcentração produtiva e melhoria nas condições de vida.

Esta observação é reforçada quando comparamos os PIBs per capita, as taxas de crescimento e o IDH dos municípios. Neste quesito, o município de Presidente Kennedy (ES) é líder disparado: seu PIB per capita de $R \$ 513,1$ mil, em 2015, foi o maior do Brasil e quase o dobro do segundo colocado, Paulínia (SP). Para se ter uma ideia da grandeza do PIB per capita do município capixaba, o do Brasil foi de $R$ \$29,3 mil e o do Espírito Santo, $\mathrm{R} \$ 30,6$ mil. Quando comparamos o indicador anterior com o Índice de Desenvolvimento Humano - IDH, Presidente Kennedy fica apenas na 66 posição dentre os 78 municípios capixabas e na $2.964^{\text {a }}$ dentre os 5.665 municípios brasileiros existentes em 2010. O mesmo acontece com Itapemirim (ES), o segundo maior PIB per capita capixaba, mas tão somente o 69 IDH estadual e 3.030ํㅡ brasileiro. Em outras palavras, tantas riquezas produzidas em seus territórios não representam desenvolvimento social e humano para suas populações ${ }^{20}$.

QUADRO 1 - BRASIL: Posição de municípios selecionados no PIB per capita, IDHM e IDH Renda

\begin{tabular}{|l|c|c|c|}
\hline \multirow{2}{*}{ MUNICÍPIO } & \multicolumn{2}{|c|}{ Posição nacional no: } \\
\cline { 2 - 4 } & PIB per capita* & IDHM** & IDHM Renda** \\
\hline Presidente Kennedy (ES) & 513.134 & $2.964^{\circ}$ & $3.082^{\circ}$ \\
Paulínia (SP) & 276.972 & $56^{\circ}$ & $54^{\circ}$ \\
Louveira (SP) & 271.206 & $157^{\circ}$ & $112^{\circ}$ \\
Triunfo (RS) & 268.381 & $940^{\circ}$ & $1.125^{\circ}$ \\
Selvíria (MS) & 246.333 & $2.386^{\circ}$ & $2.476^{\circ}$ \\
Gavião Peixoto (SP) & 228.391 & $1.331^{\circ}$ & $1.973^{\circ}$ \\
llhabela (SP) & 222.528 & $440^{\circ}$ & $621^{\circ}$ \\
São Francisco do Conde (BA) & 219.846 & $2.573^{\circ}$ & $3.003^{\circ}$ \\
São João da Barra (RJ) & 211.946 & $2.642^{\circ}$ & $2.013^{\circ}$ \\
Araporã (MG) & 200.226 & $1.665^{\circ}$ & $2.268^{\circ}$ \\
Barueri (SP) & 182.225 & $87^{\circ}$ & $76^{\circ}$ \\
Ilha Comprida (SP) & 180.774 & $1.154^{\circ}$ & $1.712^{\circ}$ \\
Pinhal da Serra (RS) & 180.660 & $3.115^{\circ}$ & $1.555^{\circ}$ \\
Jaguariúna (SP) & 171.530 & $100^{\circ}$ & $119^{\circ}$ \\
São Gonçalo do Rio Abaixo (MG) & 169.568 & $2.938^{\circ}$ & $2.695^{\circ}$ \\
Piratuba (SC) & 166.371 & $400^{\circ}$ & $698^{\circ}$ \\
São Simão (GO) & 162.545 & $1.301^{\circ}$ & $333^{\circ}$ \\
Cajamar (SP) & 161.339 & $1.081^{\circ}$ & $1224^{\circ}$ \\
Campos de Júlio (MT) & 158.122 & $667^{\circ}$ & $56^{\circ}$ \\
Extrema (MG) & 153.743 & $965^{\circ}$ & $840^{\circ}$ \\
\hline xAnO 2015. AnO & & \\
\hline
\end{tabular}

${ }^{\star}$ Ano $2015 .{ }^{* *}$ Ano 2010.

Fonte: IBGE/PIB Municipal. PNUD/IPEA/João Pinheiro. Elaboração dos autores.

${ }^{20}$ Ressalta-se, no entanto, que o IDH é um indicador cujo uso requer cuidado apesar de sua validade ser, normalmente, superdimensionada pelos pesquisadores e gestores públicos. 
O Quadro 1 acima apresenta a relação dos vinte maiores PIBs per capita municipais e o posicionamento desses municípios em relação ao IDHM e IDHM Renda. Duas observações são importantes. A primeira é a falta de correlação entre um alto PIB per capita e um elevado IDH. A segunda é a presença marcante de municípios que têm sua economia atrelada a base de exploração e beneficiamento de recursos naturais, e pequena população. Além desses, destacam-se aqueles ligados a políticas de atração de investimentos ("Guerra Fiscal") ou que se beneficiam de vantagens locacionais por estarem em áreas metropolitanas ou próximas de grandes cidades.

De qualquer forma, o que a discrepância em casos como estes indica - e que poderia ser multiplicada por outros exemplos facilmente verificáveis no Brasil, especialmente os municípios de base mineral - é que geração e distribuição da riqueza são coisas diferentes. A primeira não representa, necessariamente, melhoria das condições sociais, embora seja elemento importante para a construção destas. Por isso, os indicadores selecionados apontam que o esforço para elevação no nível de bem-estar de municípios com elevado PIB per capita é grande.

Não se pode desconsiderar que muitos municípios têm seus territórios utilizados prioritariamente como plataformas de produção de riqueza sem que a mesma fique retida neles. A riqueza produzida no Brasil, a despeito da maior participação do interior, continua, do ponto de vista espacial, sendo majoritariamente apropriada nas capitais estaduais e regiões metropolitanas, além de vazar para outros países.

Há que se destacar que o uso do PIB municipal não se restringe apenas as possibilidades de análise econômica das regiões brasileiras, a partir da menor escala federativa. Seu uso possibilita, também, a definição de áreas elegíveis para a ação da política regional, como no caso da PNDR que utilizou a variação do PIB como um dos critérios de classificação das microrregiões brasileiras. Sobre os limites e possibilidades do seu uso e a atualização das tipologias da PNDR com base na nova série do PIB Municipal indica-se a leitura de Porto e Macedo (2017)

\section{CONSIDERAÇÕES FINAIS}

Este artigo discutiu a utilização da nova série do Produto Interno Bruto dos Municípios - Referência 2010, divulgada pelo IBGE, para o entendimento da dinâmica 
econômica das regiões, no quadro de referência da política regional no Brasil, e para o entendimento, ainda que limitado, da dinâmica regional brasileira. A nova série do PIB municipal tem a vantagem de permitir análises mais consistentes, por colocar os valores numa mesma base de referência, assim como possibilita comparações inter e intrarregionais.

Um breve diagnóstico da dinâmica econômica regional brasileira, por meio da análise do PIB dos municípios, evidenciou características fundamentais sobre 0 desempenho da economia nesse início de século $\mathrm{XX}$, resultantes da heterogeneidade do conjunto de municípios. Dentre elas, destacamos: a) a histórica e persistente concentração espacial da riqueza; b) a continuidade do processo de desindustrialização, com perdas de participação da indústria de transformação; c) a dependência que ampla maioria dos municípios tem dos gastos do setor público; d) um lento, mas contínuo, processo de desconcentração econômica; e) além da falta de correlação entre elevados PIBs per capita com elevação do bem estar e da qualidade de vida da população dos municípios.

\section{REFERÊNCIAS}

BRASIL. Decreto no 6.047, de 22 de fevereiro de 2007. Institui a Política Nacional de Desenvolvimento Regional e dá outras providências [Online]. Brasília: Presidência da República. Disponível em: <http://www.planalto.gov.br/ccivil_03/_ato20072010/2007/decreto/D6047.htm>. Acesso em 12 jul. 2016.

BRASIL. MINISTÉRIO DA INTEGRAÇÃO NACIONAL. A Política Nacional de Desenvolvimento Regional - Sumário Executivo. Brasília: SDR/MI, 2003, 32 p. Disponível: <http://www.mi.gov.br/c/document_library/get_file?uuid=240b7eb3-af5d458a-ad65-1e9f4d5e9095\&groupld=24915 >. Acesso em: 23 dez. 2016.

BRASIL. A PNDR em dois tempos: a experiência apreendida e o olhar pós-2010. Brasília, MI/SDR, 2010. <http://www.mi.gov.br/documents/10157/c5460640-8b23-43deba2a-1fd0ee391aa0>. Acesso em: 17 set. 2016 .

CANO, W. Descontração Produtiva Regional do Brasil 1970-2005, São Paulo: UNESP, 2008, 294 p.

INSTITUTO BRASILEIRO DE GEOGRAFIA E ESTATÍSTICA. Produto Interno Bruto dos Municípios. 2ª ed., Rio de Janeiro, IBGE, 2008a. (Série Relatórios Metodológicos, v. 29). Disponível em: <http://biblioteca.ibge.gov.br/visualizacao/livros/liv41219.pdf>. Acesso em: 12 fev. 2017. 
INSTITUTO BRASILEIRO DE GEOGRAFIA E ESTATÍSTICA. Regiões de influência das cidades - 2007. Rio de Janeiro, IBGE, 2008b.

INSTITUTO BRASILEIRO DE GEOGRAFIA E ESTATÍSTICA. Nota metodológica da série do PIB dos Municípios - Referência 2010. Rio de Janeiro, IBGE/DPE/CONAC, set., 2015a. Disponível em:

<ftp://ftp.ibge.gov.br/Pib_Municipios/Notas_Metodologicas_2010/NotaMetodologicaPIB_ MunicipiosRef2010.pdf>. Acesso em: 12 fev. 2017.

INSTITUTO BRASILEIRO DE GEOGRAFIA E ESTATÍSTICA. Nota metodológica da série retropolada (2002-2009). PIB dos Municípios - Referência 2010. Rio de Janeiro, IBGE/DPE/CONAC, set., 2015b. Disponível em:

<ftp://ftp.ibge.gov.br/Pib_Municipios/Notas_Metodologicas_2010/NotaMetodologicaPIB_ Munic\%C3\%ADpiosRetropolacao.pdf_>. Acesso em: 12 fev. 2017.

INSTITUTO BRASILEIRO DE GEOGRAFIA E ESTATístICA. Produto Interno Bruto dos Municípios - ano de referência 2010. $3^{\text {a }}$ ed. Rio de Janeiro, IBGE/DPE/CONAC, 2016. Disponível em: < https://biblioteca.ibge.gov.br/visualizacao/livros/liv97483.pdf>. Acesso em: 2 de fev. 2018.

INSTITUTO BRASILEIRO DE GEOGRAFIA E ESTATÍSTICA. Produto Interno Bruto dos Municípios - 2010-2015. Rio de Janeiro, IBGE/DPE/CONAC, 2017. Disponível em: $<$ https://biblioteca.ibge.gov.br/visualizacao/livros/liv101458.pdf>. Acesso em: 2 de fev. 2018.

MACEDO, F.; PIRES, M.; SAMPAIO, D. 25 anos de Fundos Constitucionais de Financiamento no Brasil: avanços e desafios à luz da Política Nacional de

Desenvolvimento Regional. EURE, Santiago (Chile), v. 43, № 129, maio 2017, 257-277.

PORTO, L. R. Urbanização e dinâmica econômica na rede urbana do estado da Bahia (1940-2010): o caso de Vitória da Conquista-BA. Dissertação (Mestrado em Desenvolvimento Econômico), Campinas-SP, Unicamp, 2016.

PORTO, L.; MACEDO, F.C. Atualizando as tipologias das Política nacional de Desenvolvimento Regional. In: SEMINÁRIO INTERNACIONAL DE DESENVOLVIMENTO REGIONAL, VIII, 2016, Santa Cruz do Sul. Santa Cruz do Sul: UNISC 2017. Disponível em: < http://online.unisc.br/acadnet/anais/index.php/sidr/article/view/16685/4325>. Acesso em: 06 fev. 2018.

SAMPAIO, D. P. Desindustrialização e estruturas produtivas regionais no Brasil. 2015. 267 fls. Tese (Doutorado em Desenvolvimento Econômico) - Instituto de Economia, Universidade Estadual de Campinas, Campinas, 2015.

Recebido em: Setembro de 2017

Aceito em: Dezembro de 2017 